\title{
GPS TEC and ITEC from digisonde data compared with NEQUICK model
}

\author{
J.-C. Jodogne ${ }^{1}$, H. Nebdi ${ }^{1}$, and R. Warnant ${ }^{1 *}$ \\ ${ }^{1}$ Institut Royal Météorologique, 3 Avenue Circulaire, B-1180 Bruxelles, Belgium \\ *Royal Observatory of Belgium
}

\begin{abstract}
At the Dourbes station, a digisonde 256 is colocated with a Turbo Rogue GPS receiver. Real time processing of the digisonde data gives the electron density profile and the ITEC value (SAO file) for each sounding. The GPS receiver produces data that are treated at the Royal Observatory in order to extract a vertical TEC. Running the wellknown NeQuick ionospheric model allows to compute vertical TEC values. Comparisons of the results obtained in 1996 and 2001 by these different approaches are shown.
\end{abstract}

\section{Introduction}

The use of empirical models for the Total Electron Content (TEC) appears to increase in different applications. We benefit of the co-location of two systems able to provide TEC estimations to compare with such a model.

NeQuick model is a one adopted by the COST 251 Action and updated during the succeeding COST 271 Action till now (Leitinger et al., 2002). To be short, the CCIR coefficients are used for foF 2 and we run the software program with the monthly averaged solar flux for each hour at the Dourbes location. The profilers for E-, F1- and F2-regions are Epstein functions with different parameters for bottom and top parts. The topside ionosphere is simply a semi-Epstein layer. One of the features of the NeQuick model is to compute the electron content between any starting point (lat, long and height) and ending point in straight line. We limit ourselves to vertical direction. Two graphs for respectively 2001 (high solar activity) and 1996 (low solar activity) displayed at Fig. 1 give an idea of the model behaviour.

A Turbo Rogue receiver was installed at the top of the main building of the Dourbes station for derivation of GPS TEC values (Warnant and Jodogne, 1998). We remove all data from GPS satellite whose elevation is less than $88.5^{\circ}$.

Correspondence to: J.-C. Jodogne

(jodogne@oma.be)
At the Dourbes station a digisonde 256 with the Artist software produces hourly ionograms. The SAO output file gives the usual characteristics and an ITEC (Ionospheric TEC) up to infinity (Huang and Reinisch, 2001). It is such a value automatically produced that was used for this work.

\section{NeQuick compared with GPS TEC}

In order to see the data compared with the model we choose several months. GPS TEC was produced each quarters of the hour. We compute the median, the lower and upper quartiles, the maximum and the minimum for each quarter of hour of the month. The graphs present these values. We show the hourly NeQuick values as diamonds on the graphs. Typical season's months are displayed (January, March, June and September) for the years 1996 and 2001 (Figs. 2 and 3). To easily see the contrast between the two years we put four graphs on one panel.

When the solar activity was low the model gives higher values except for September 1996. For high solar activity values are quite good for January and especially for March but too small during June and September 2001.

\section{NeQuick compared with Ionospheric Total Electron Contents}

As for the GPS data, we compute the same statistical parameters for the year 2001. However GPS TEC were produced each quarter of hour but we record hourly ionograms only. Again we show NeQuick values as diamonds on the graphs (Fig. 4).

The median's data from January and March are always below the model's values while they are higher in June during day's hours. In September the agreement between model and experimental values is very good, especially during the first half of the day. 

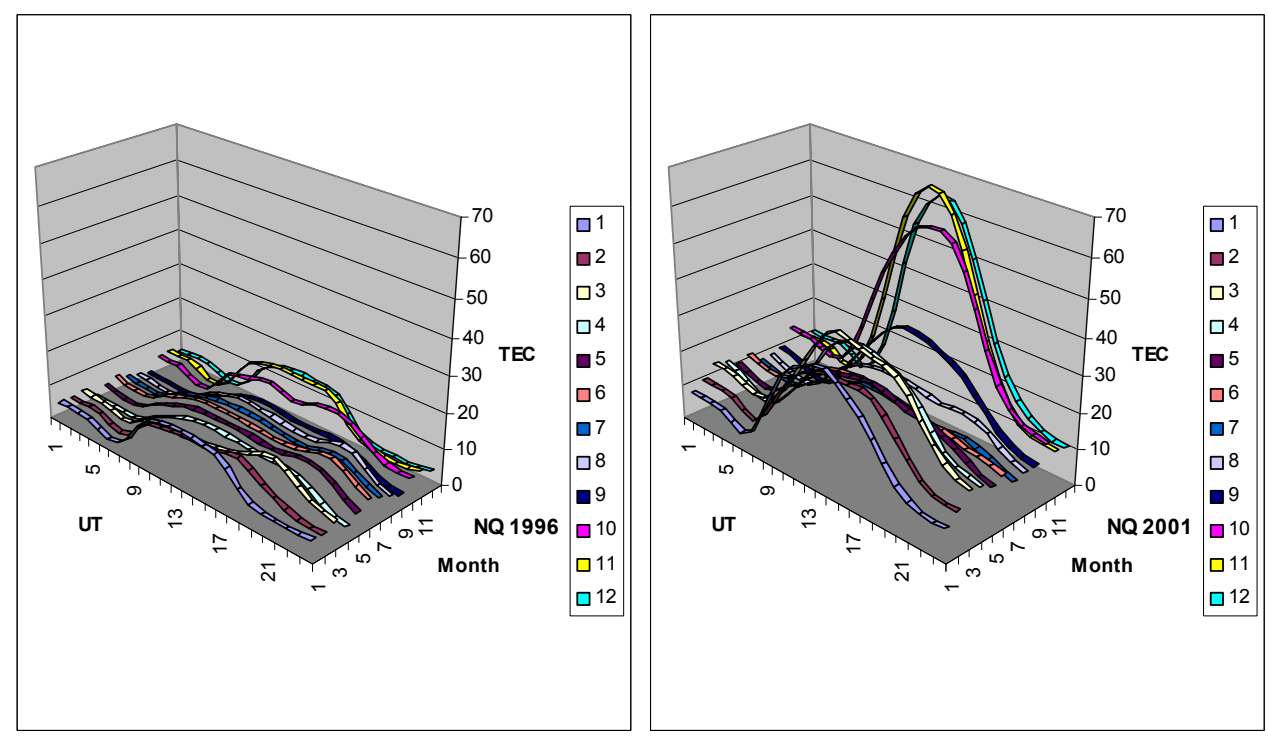

Fig. 1. TEC values up to $20000 \mathrm{~km}$ from the NeQuick model for 1996 and 2001.
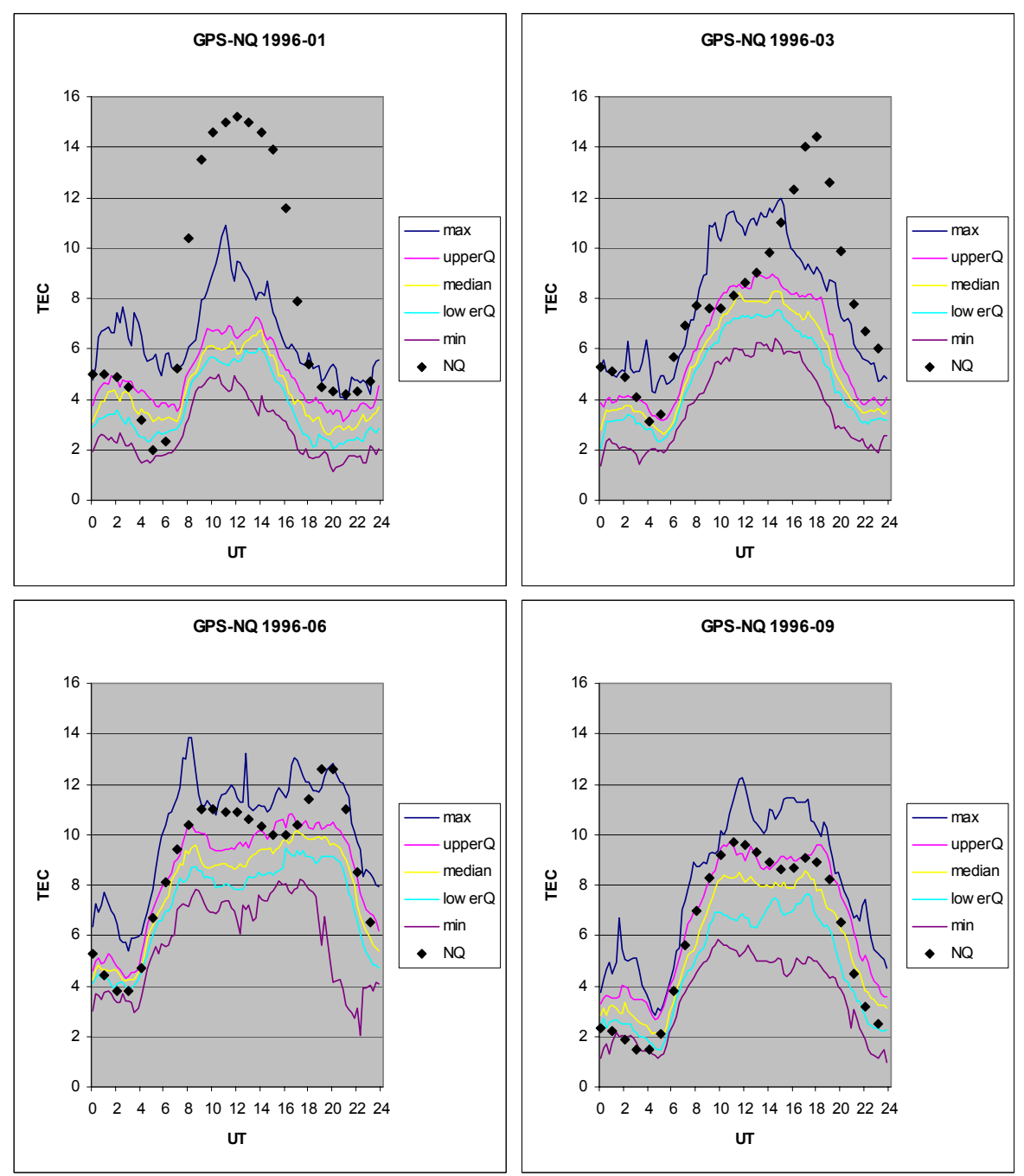

Fig. 2. GPS TEC versus TEC from model for typical season's months of 1996. 

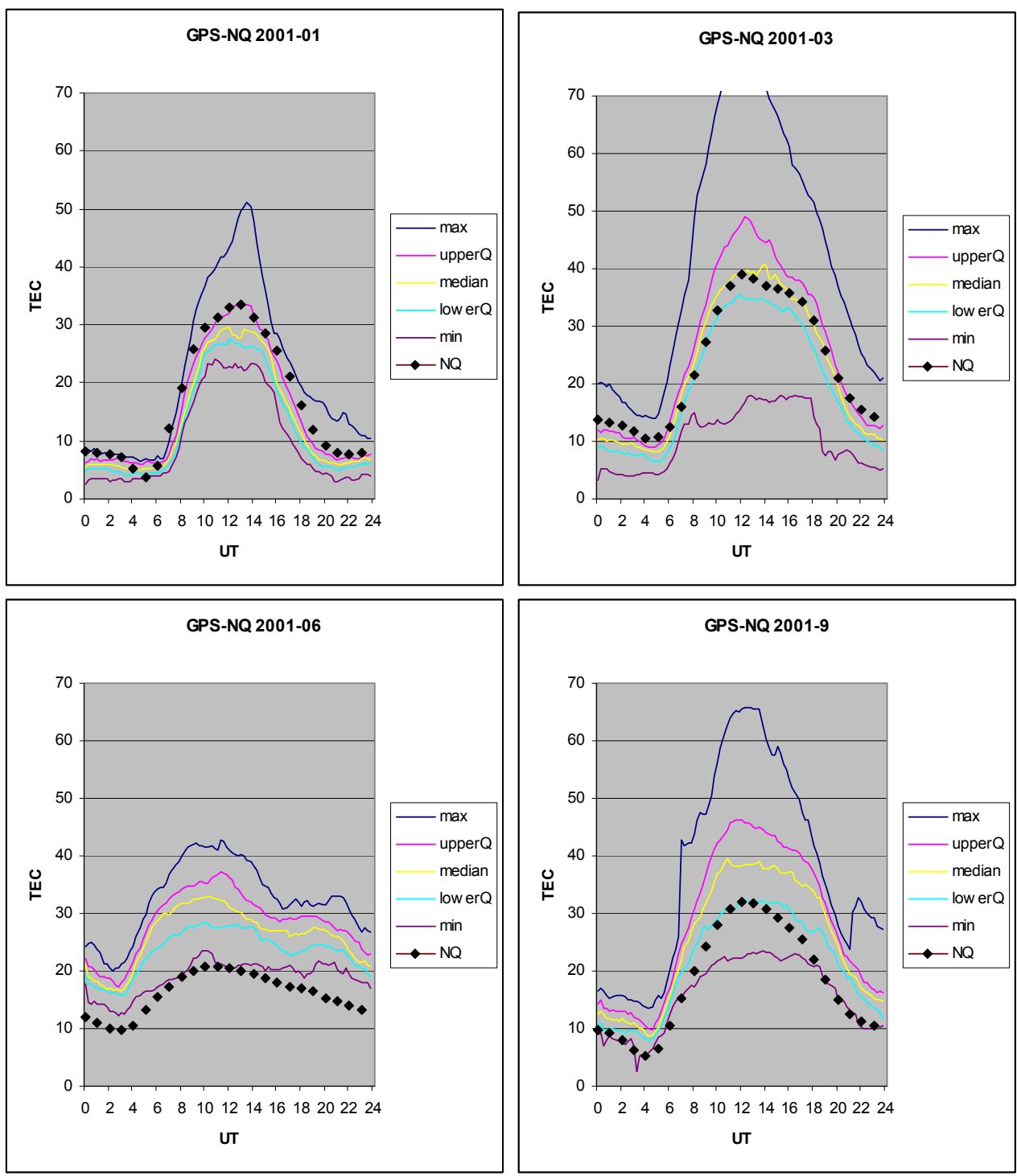

Fig. 3. Same as Fig. 2 but for year 2001.

In March 2001 we run the digisonde each 30 min. When these data are taken into account we get the graph of Fig. 5. The influence of waves in the ionosphere appears clearly. For some hours, the upper quartiles, medians and lower quartiles have nearly the same values despite the wavy structure (2:00, $3: 00,8: 30,10: 30,12: 30,13: 30,19: 30,20: 30,22: 30$ ). For GPS TEC during this month, the difference between the upper quartile and the lower quartile is small and the model fits quite well the data.

\section{Ionospheric Total Electron Contents compared with GPS TEC}

We display the medians for GPS as curves and for digisonde as points (Fig. 6). The shapes of both estimations are quite similar. As well known the GPS values are always larger than those from the digisonde.

\section{Conclusions}

As TEC estimations from GPS used in this work are means from about 30 samples during $15 \mathrm{~min}$, it is understandable that the scatter of the GPS data is lesser. The night's data of the two experimental systems seems to be closer (except for June) to the model's values than those of the day. During daytime the discrepancies can reach more than 50\% (January 1996) for GPS.

As this study is made with limited data series we don't want to give final conclusions. However the order of magnitude of the model's values are good, in particular for January and March 2001 were medians of GPS TEC and model's values almost coincide. 

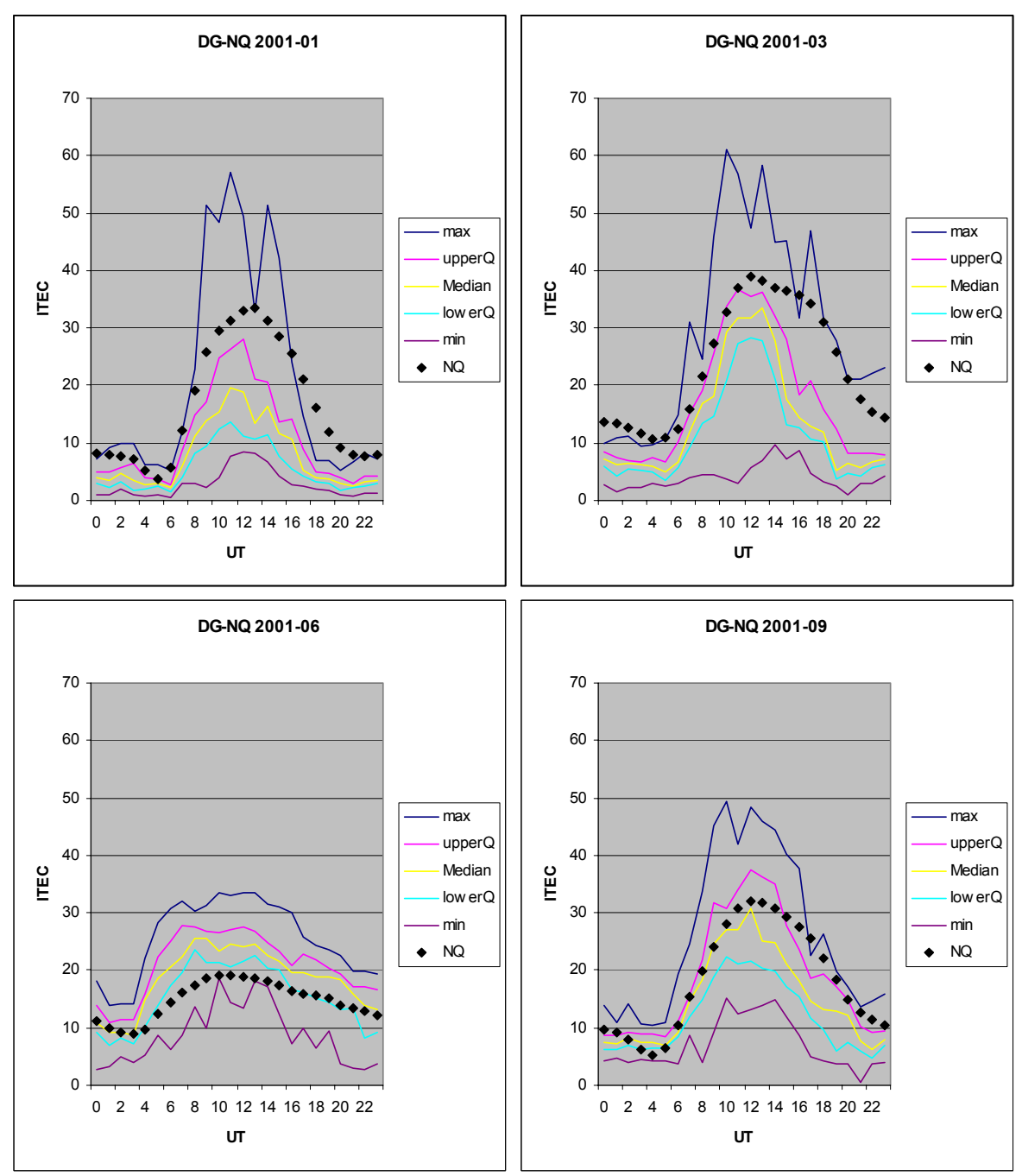

Fig. 4. Same as Fig. 3 but ITEC values from SAO files of the digisonde.

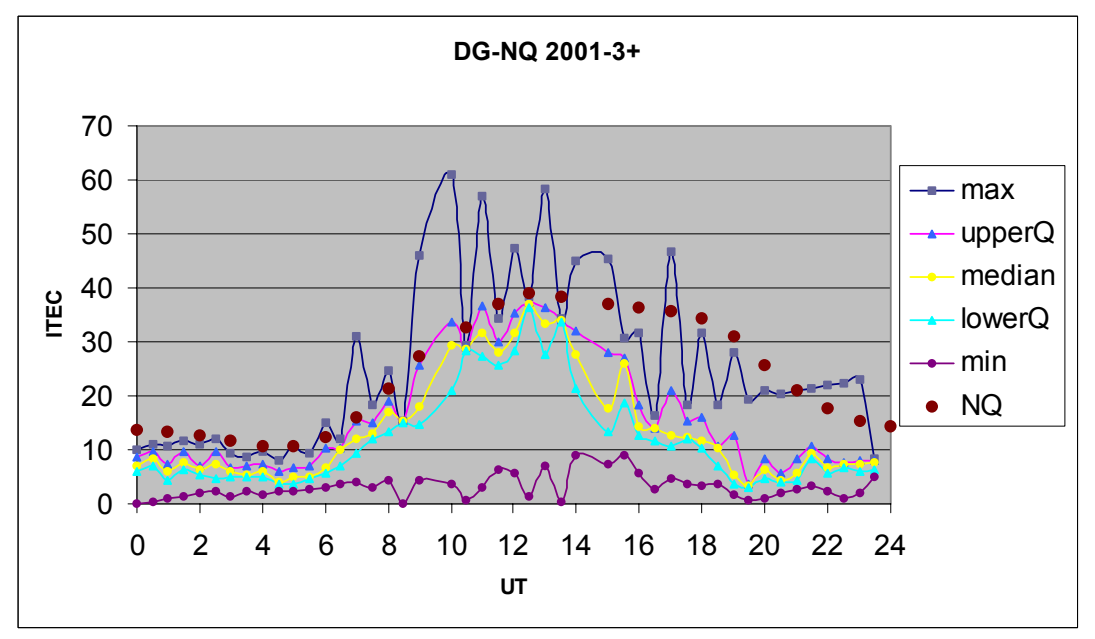

Fig. 5. ITEC data for each $30 \mathrm{~min}$ sounding and March 2001. 

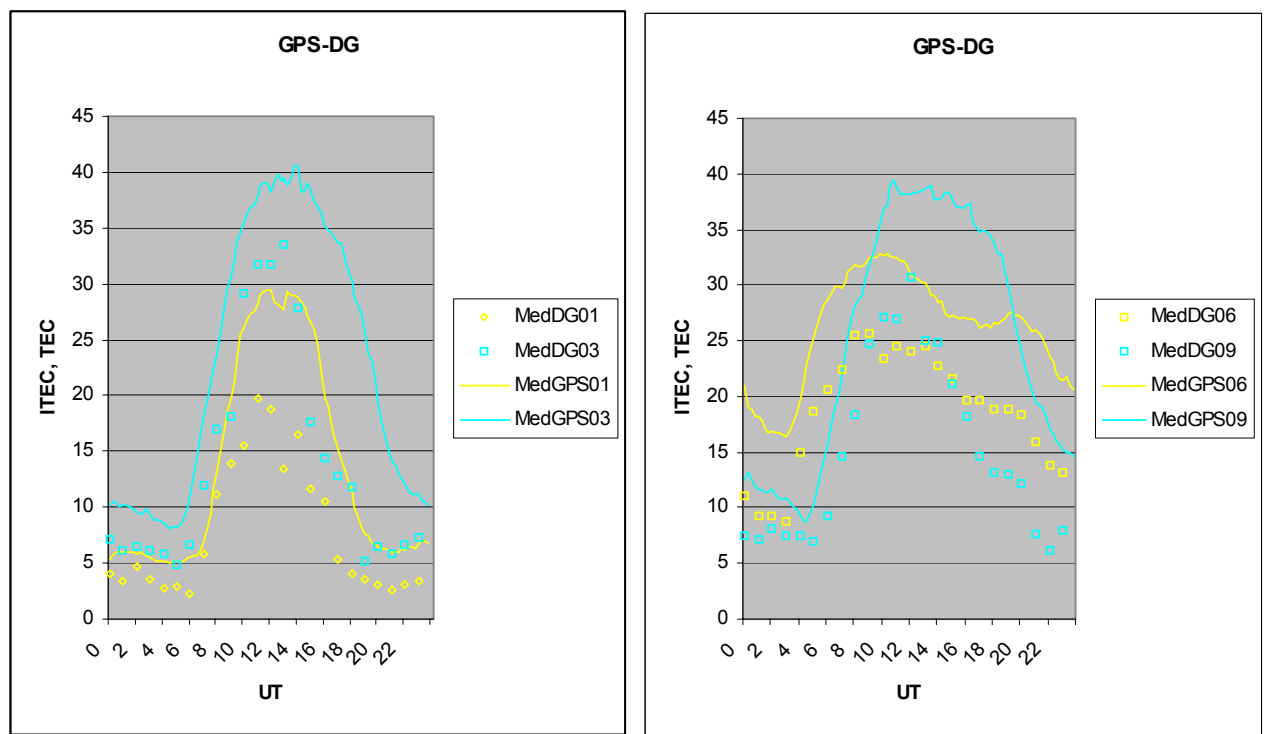

Fig. 6. Medians for digisonde ITEC (points) and GPS TEC (curves) during January and March (left panel) or June and September (right panel).

\section{References}

Huang, X. and Reinisch, B. W.: Vertical electron content from ionograms in real time, Radio Science, 36, 2, 335-342, 2001.

Leitinger, R., Radicella, S., and Nava, B.: Electron density models for assessment studies - new developments, Acta Geodet. Geophys. Hung. 37, 183-193, 2002.
Warnant, R. and Jodogne, J.-C.: A comparison between TEC computed using GPS and Ionosonde measurements, Acta Geodet. Geophys. Hung. 33, 147-153, 1998. 